\title{
Data Driven Root Cause Analyses in Multistage Manufacturing Utilising Life Cycle Wide Product Information
}

\author{
Živorad BELIĆ, Vidosav MAJSTOROVIĆ, Dragan ĐURĐANOVIĆ, Snežana KIRIN
}

\begin{abstract}
Root cause analyses in multistage manufacturing represents inspiration for constant improvement of existing methodologies and implementation of new ones. Using quality information data from manufacturing stage and customer perception, robust model that can be utilized in line in actual manufacturing plant is created. In this paper, a new approach for managing dimensional quality and improvement of the product geometry has been presented. New methodology was checked and then applied in major automotive factory.
\end{abstract}

Keywords: key characteristics; multistage manufacturing process; root cause analyses; quality management; stream of variation

\section{INTRODUCTION}

Geometry of a product defines its shape and dimensions, and is monitored by spatially tracking the state of its geometric elements (points, lines, angles and shapes) relative to a set of predefined conditions (specifications). Variations of geometric elements of a product could significantly affect the functionality and aesthetics of the product, and it is clear why monitoring of product geometry during manufacturing is of paramount importance, especially in a large manufacturing system, such as a modern automotive factory (Tab $6 \mathrm{~mm}$ ) Upon its acceptance the article is categorized as follows: original scientific paper, preliminary notes, subject review and professional paper.

Manufacturing of a product nowadays is usually performed via a large number of operations [1-4], as illustrated in Fig 1. Each of constituent operations can potentially introduce errors into the product, with those errors getting transformed and accumulated as the work pieces progresses through successive operations. Consequently, it becomes very challenging to root causes of problems in product geometry, once they are detected.

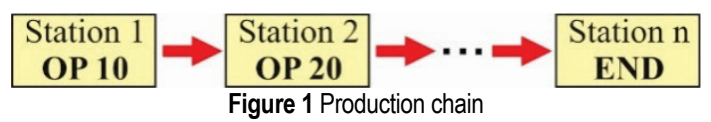

Root cause analysis is an objective, structured approach for identifying and determining the most probable causes of undesired event and considers factors that result in the nature, magnitude, location, or timing of harmful outcomes (consequences) stemming from past risk events, or factors that may lie behind future risk events [5].

Stream of Variation (SoV) methodology, originally proposed in the seminal work by $\mathrm{Hu}$ [6], offers an avenue for root cause identification based on models of the flow of manufacturing errors in multistage manufacturing systems. E.g. a linear state- space model of dimensional errors in automotive body assembly lines developed in [7] and refined in [8] was employed for root cause identification in [9]. Similarly, multiple studies considered SoV model based approaches for root cause identification in multi station machining systems [10-12].
Development and implementation of a new product / process in multistage manufacturing consist of three stages:

1) design phase,

2) ramp up and

3) full production phase.

The largest number of papers in this field is related to preventive action, or prediction of unwanted events, simulations and calculations that define the best initial parameters. Their approach is based on creating mathematical, physical and empirical models, which are related only to the first two phases launch and ramp up phase [13-15]. New concept, which is the theme of this paper, is based on using data from quality information in manufacturing stage. In other words, new approach is focused on full production phase.

Contrary to the SoV models, which are still not robust enough for being used in real time manufacturing, approach introduced in this paper uses real time data in manufacturing which makes it very robust. This creates model that can be utilized in line in actual manufacturing plant.

In this paper, new approach for identification of root causes of problems in product quality is proposed. This approach avoids the time-consuming and highly errorsensitive stage of model-building, which is necessary for SoV based methods. Instead, it relies on in-line manufacturing data routinely gathered in the process of assuring dimensional product quality in each stage of the manufacturing system (in-process quality measurements of the work pieces), as well as data from the final dimensional control stage and customer perception data about the final product. Contrary to SoV methodology which is time consuming, new model provides possibility for rapid development of a model.

This paper for the first time provides solution for monitoring and management of product quality with:

- robustness,

- rapid development of a model and

- application in real time manufacturing.

The foundation of newly proposed methodology is the new modelling framework which will be discussed in the rest of the paper. New model, so called IMOG 
(Interoperable Model to Obtain Geometry), is utilized in line in actual manufacturing.

\section{METHODOLOGY OF IMOG MODEL}

The basic principle of monitoring the dimensional quality [16-25] is by monitoring the key characteristics $(K C)$ [26] of a product. Which characteristics are $K C$ and what are their codes, comes from the Control Plan of the product. Monitoring the $K C$ is a statistical approach, which involves partial consideration: quality inspection, quality assurance, and quality maintenance. As it was previously mentioned, this method has two inputs that represent quality of a product. Quality information from manufacturing stage come from the tool called Status of Geometry (SG), which detects state of monitored/measured $K C$ inside clusters of a product. The second inputs of data came from Quality Assurance (QA) matrix, which provides identification of any problem on a final product.

This approach, by interactive engagement of mentioned tools, provides a unique and overall assessment of the state of $K C$, without giving priority to one of them. In this way, $K C$ which cause the problem, are clearly defined, and priority in solving problems is properly and clearly defined.
New approach allows simple localization of a problem, which eliminates need for comprehensive checks of all individual geometric $K C$. Gathering of all influential parameters and their analysis refers to all clusters of body in white in multi-level body assembly process (Fig. 2).

As it is already mentioned, there are two inputs of data which represent the quality of the product:

First input is in correlation with body in white assembly phase. In this phase geometric characteristics of the parts, sub-assemblies and assemblies are in monitoring (quality information from manufacturing stage - SG). Data represent the difference of $K C$ measured in real production and product design.

Second input of data comes from customer perception of complete product (vehicle). Actually, the plant quality checks the final product with the "eyes of the customer" and gives the final evaluation. All found anomalies (dimensional errors, deformations, paint faults, etc.) are registered and evaluated in so cold QA matrix. Recognized dimensional errors of a complete product are in correlation with geometrical issues of parts- clusters. Mostly, those errors are seen as gaps and flushes.
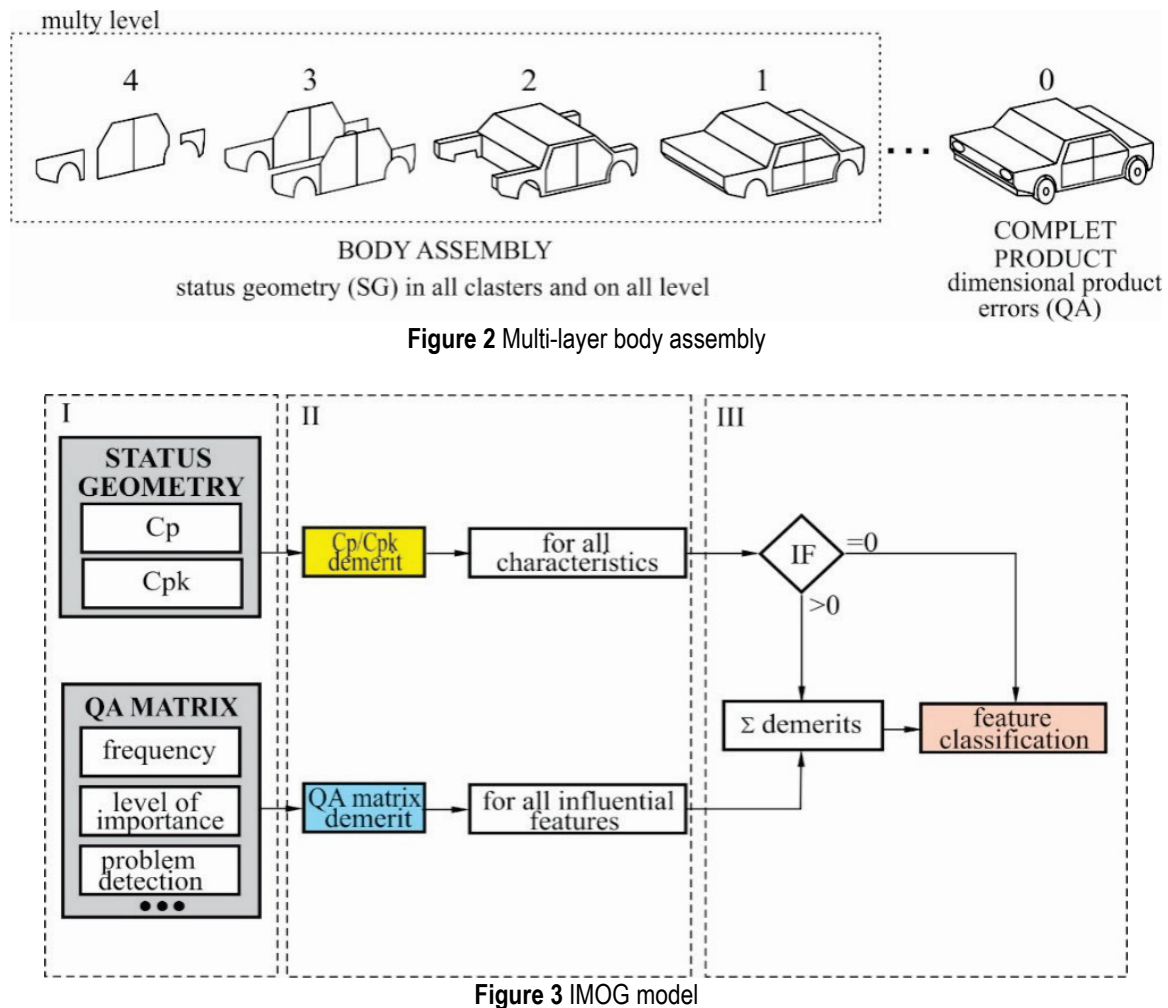

The cluster is zone of sub-assembly or assembly with all its characteristics, which are monitored and analysed as a unit (for example: doors, door opening, fender etc.).

IMOG model is just mentioned but not worked out in [27]. It is composed of three parts:

- starting parameters,

- defining the influential values of $K C$ and

- $\quad$ classification of $K C$ (Fig. 3).

I - starting parameters represent analysis of SG and QA matrix. The parameters of SG are related to monitoring and statistical analysis of all clusters and geometric characteristics within them. Among all the anomalies of a product that are detected in QA matrix, only those which cluster geometry may have an impact on (gaps and flushes) are taken into consideration.

II - defining influential values of key characteristics is equally analyzed according to the SG and QA matrix. Influential value of $K C$ of $S G$ directly depends on the value of capability index ( $C p$ and $C p k$ ) [28]. Influential value of QA matrix are negative points (demerits) for each 
registered anomaly. Negative points are assigned to all $\mathrm{KC}$ that have potential impact on anomaly itself.

III - classification of characteristicsis performed after defining the influence of $K C$ from $S G$ and QA matrix. All assigned values (demerits) are summarized and allinclusive, unambiguous quality assessment is obtained and together affects the detected problem. The existence of the IF function is noticed. It provides that if in the case where certain $K C$ from $S G$ has no demerits $(C p>1.33$; $C p k>$ 1.33 ), the total sum of demerit will be reduced to zero. If $S G$ indicates that some $K C$ is good, or statistical data analysis shows that the $C p$ and $C p k$ values for particular $K C$ are above required value, it means that this $K C$ cannot have an impact on the following problem. It means that the root cause of a problem should be searched for somewhere else in the process of product production and not within the cluster geometry (dimensional quality) or in process of Body Shop.

As with all existing approaches of monitoring and quality management, as well as with concept IMOG, it is necessary to have a certain mathematical tool. Standard methods are not the most appropriate. For the comprehensive analysis of a situation and determining the causes of existing deviation, using IMOG, and also to achieve appropriateness by monitoring a large number of clusters, new software has been developed. It is suitable because of its possibilities:

- insight into the current state of the process (at any time),

- monitoring the causal flows (lines) and

- a large number of data operated effortlessly (basic and additional).

The important thing is that it analyses the large number of parameters and, in short time and with great precision, gives outputs.

For the mentioned operations and clusters, IMOG determines and estimates potential impact on one or more characteristics. This determines:

- which are the most critical operations in the production process,

- which operations should be given special attention to in terms of autonomous or preventive maintenance (WCM methodology)

- operations which can serve as a model of a specific zone, etc.

The result of the analysis is given through four outputs: - condition of all product characteristics, which makes it easier to determine priorities

- condition of product characteristics for each individual cluster,

- a sum of demerits for all clusters and

- a sum of demerits for all geometry operations in body assembly.

As it has already been said, this method requires a large number of input data and its processing requires the use of an appropriate mathematical apparatus. In Fig. 4 the main frame of IMOG application is shown. A few sub algorithms are branching from it, but with software explanation, this paper would lose its aim, which is IMOG methodology.
Description of the software itself would be a new paper which still has not been published.

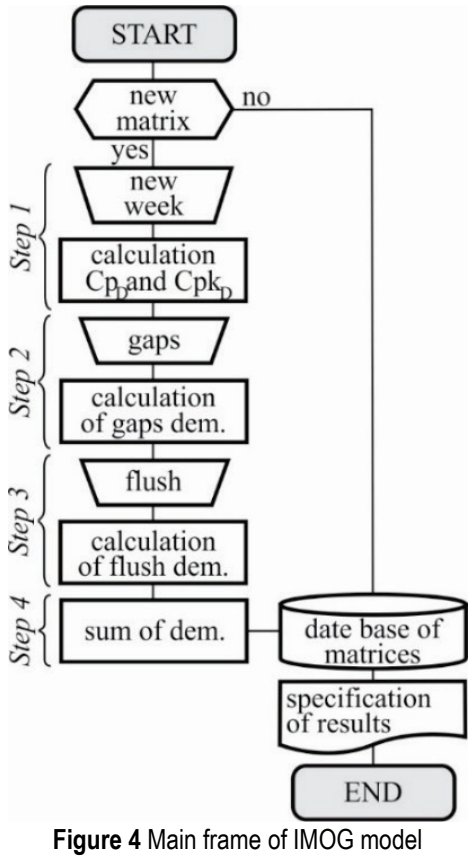

After initiation of the routine of the main algorithm, one can access the already existing database with certain matrices with old but valid data, or can choose the process of forming a new matrix with new data.

The process of forming of a new matrix consists of the following steps:

- $\quad$ selection of the week of measurements and calculation of $C p / C p k$ demerits of all $K C$,

- $\quad$ entry of the gaps status,

- entry of the flash status,

- $\quad$ summarizing demerits.

Step 1 includes two things. The first is setting the name of the matrix, i.e. base for the entry and data processing. It starts in the order from the beginning of the year. The newly formed database is filled with information about the state of geometry ( $C p$ and $C p k$ status of all $K C$ ). When new data are accepted the software makes the calculation of demerit values. In other words, software compares the actual values of $C p$ and $C p k$ with limit values. Application, without the possibility of human error, assigns demerits to all characteristics. Since there are several hundreds of $K C$ (e.g. 450) the counter repeats the calculation for each characteristic.

Step 2 presents the entry of demerit for gap anomalies identified in QA matrix. Software contains mapping of product with a large number of fields (e.g. 190) that define the possible locations of the anomaly. Demerits are entered in the appropriate mapping fields (Fig. 5), and timer ensures check through all fields. For every field, software checks database of all $K C$ that have influence on certain anomaly and assigns each of them a demerit value.

Step 3 is performed in exactly the same way as Step 2. Only difference is that mapping is filled with demerit values correlated with flush anomalies from QA matrix of the product. 


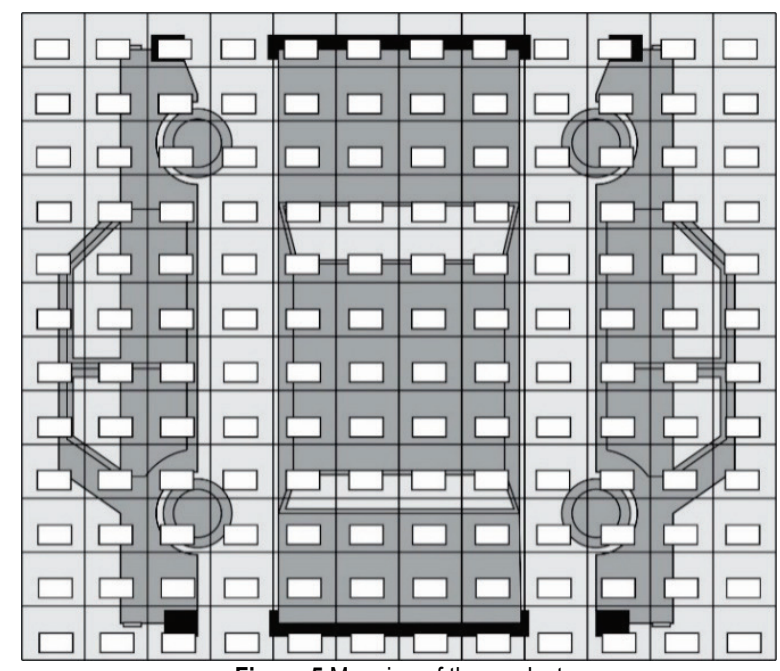

Figure 5 Mapping of the product

Step 4 is a sum of demerits of previous three steps. If it is determined that the sum of demerits of first step $(S G)$ for one characteristic is zero, the final sum of demerit for this characteristic is also zero (IF function; Fig. 3). Otherwise, demerit value from the first step is added to the demerit values of the second (gaps) and the third (flush) step and that represents further (acting) value.

Demerit summing from all input variables (from SG and QA matrix), provides status of $K C$ of product. In this way, more realistic picture of $K C$ that has influence on the quality of final product is obtained. Additionally, more realistic priorities and the critical operation of the process are provided.

\section{EXPERIMENTAL RESULTS}

The concept IMOG was implemented in major automotive factory. As an illustration some results will be shown. New concept provides data through CMM (Coordinate Measurement Machine), with approximately $450 K C$ (and several thousand secondary characteristics) and with significantly greater precision, which is about $0.01 \mathrm{~mm}$. It should be emphasized that with this kind of measurement not every product is controlled, but only statistical sample.

$\mathrm{KC}$ of individual clusters and their condition are not of great interest for an end-user but overall quality of the final product (Fig. 6). That was the reason to start from QA matrix, which generated the anomaly: bad gap between front and rear doors (Fig. 7). Since the QA Matrix does not consider what the root cause of the anomaly is, the new approach placed the focus on all key characteristics that can have geometrical effect on the anomaly.

According to the developed mapping of the product of influential clusters, for example Front Left Door and Rear Left Door, key characteristics in the observed zone are specified. In this case, key characteristics are: $15648 \mathrm{X}$ (characteristic label) edge on the front doors and 12684X (the position of the edge of the rear doors). Characteristic $12691 Z$, which is located in the same area, on the basis of the same mapping, has no impact on the deviation from the example, so it will not be considered further. What the mapping does not recognize is that there are characteristics that indirectly have an impact on the mentioned anomaly. These characteristics are located on several clusters and they are: $15635 \mathrm{X}$ and $15636 \mathrm{X}$ (the position of hinges on front door), 12665X and 12666X (position of hinges on rear door), $11357 \mathrm{X}$ and $11435 \mathrm{X}$ (condition of a surface for supporting door on the body side) and 11479X (edges on a rear door opening in which the tool for door lies on during installation). Of course, IMOG analyses the status of all these characteristics, but in order to simply describe the essence, through this example only two features, 15648X and $12684 \mathrm{X}$, will be considered.
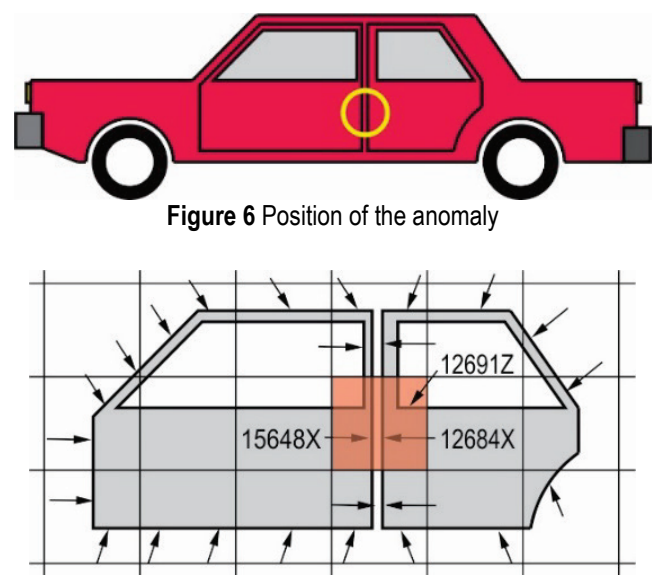

Figure 7 Mapping of a product - field with anomaly

The classical approach assigns negative evaluation to all $\mathrm{KC}$ that are measured within the cluster, where detected anomaly exists. Disadvantage of this is that the negative evaluation is unnecessarily assigned to those $\mathrm{KC}$ that even theoretically cannot have influence on observed anomaly. That leads to a generation of a large database of unnecessary data.

In mentioned examples interesting clusters are front and rear doors, as well as characteristics $15648 \mathrm{X}$ and 12684X. For each of these characteristics SG gives the value of capability indices (Tab. 1). This definition of capability indices of a process enables determination of possible deviations from the limited values and determination of demerits. Of course, the limits are different for different products and for different manufacturers, but more or less, each is guided with Six Sigma methodology and its levelling [16].

Table $1 \mathrm{Cp}$ and $\mathrm{Cpk}$ values for given characteristics

\begin{tabular}{|c|c|c|}
\hline Characteristic & $C p$ & $C p k$ \\
\hline $15648 \mathrm{X}$ & 2,68 & 1,54 \\
\hline $12684 \mathrm{X}$ & 1,22 & 0,86 \\
\hline
\end{tabular}

\begin{tabular}{|l|c|c|} 
Table 2 Value of capability indices \\
\begin{tabular}{|c|c|c|}
\hline Cap. index & Limit & Dem. value \\
\hline \multirow{3}{*}{$C p / C p k$} & $<0,33$ & 100 \\
\cline { 2 - 3 } & $<0,67$ & 50 \\
\cline { 2 - 3 } & $<1$ & 25 \\
\cline { 2 - 3 } & $<1,33$ & 10 \\
\hline
\end{tabular}
\end{tabular}

Based on users table of QA matrix it is found that the characteristics that have a negative impact (15648X and 12684X) have 150 negative points (demerits) each.

Influential value of $S G$ directly depends on the value of capability indices (Tab. 2). Limits are set by Six Sigma methodology. 
Based on Tab. 1 and Tab. 2 for specific example, demerit values for both characteristics for capability indices are obtained (Tab. 3).

Table 3 Demerit values by SG
\begin{tabular}{|c|c|c|c|c|}
\hline Characteristic & $C p$ & $C p k$ & Dem.Cp & Dem.Cpk \\
\hline $15648 \mathrm{X}$ & 2,68 & 1,54 & 0 & 0 \\
\hline $12684 \mathrm{X}$ & 1,22 & 0,86 & 10 & 25 \\
\hline
\end{tabular}

The results of classification of $K C$ for the example are given in Tab. 4.

Now, it can be concluded that the characteristic 15648X has the sum 0 (because of IF function existing chapter 2), and the characteristic 12684X sum of 185 demerits. It is clear that from the geometry point of view, cause of the problem (bad gap between front and rear doors) is characteristic $12684 \mathrm{X}$.

For the provoked problem, work task is assigned to two expert persons. Their education, work experience and responsibility for the work is similar. Identification of characteristics which are the cause of defects, and operations that are responsible for status of characteristics, can be done in two ways.

The first is the classic - ad hoc approach. With this approach after receiving data from measuring stations, next steps are - understanding of a state, analysis of a cluster and its characteristics and analysis of the processes. It is clear that this is done on the basis of empirical knowledge of responsible person (engineer).

Table $4 C p$ and $C p k$ values for the given characteristic

\begin{tabular}{|c|c|c|c|c|c|c|c|}
\hline Characteristic & $C p$ & $C p k$ & $\begin{array}{c}\text { Demerit } \\
C p\end{array}$ & $\begin{array}{c}\text { Demerit } \\
\text { Cpk }\end{array}$ & $\begin{array}{c}\text { Sum of } \\
\text { Cp/Cpk }\end{array}$ & $\begin{array}{c}\text { Demerits } \\
\text { from QA }\end{array}$ & $\begin{array}{c}\text { Sum of all } \\
\text { Demerits }\end{array}$ \\
\hline $15648 \mathrm{X}$ & 2,68 & 1,54 & 0 & 0 & 0 & 150 \\
\hline $12684 \mathrm{X}$ & 1,22 & 0,86 & 10 & 25 & 35 & & 150 \\
\hline
\end{tabular}

Another method is using the IMOG concept and its supporting software package. Large and detailed databases are done once for the complete product. Easy access to all clusters and all their particular characteristics provides practically immediate obtainment of required results. Of course, measurements which are used are the same. Usage of IMOG reduces the influence of human factor.

It should be emphasized that for concrete example there are 450 characteristics, and 80 operations. It is clear that traditional ad hoc approach certainly does not allow the quick analysis of characteristics and operations condition.

The practical application of the IMOG concept was carried out and tested in three cycles, each with 30 measurements, or a total of $3 \times 30=90$ measurements. By comparing the classical approach and the IMOG concept, the following results were achieved. In first monitoring cycle, root cause analysis was done by $28.9 \%$, in the second by $31.3 \%$ and in third by $34.5 \%$. Average for the whole period is $\sim 31.6 \%$. The reference time is the time that corresponds to the classic - ad hoc approach. It means that time using IMOG is decreased compared to the classical approach, expressed in percentages.

Diagrams in Fig. 8 illustrate all explained from above.

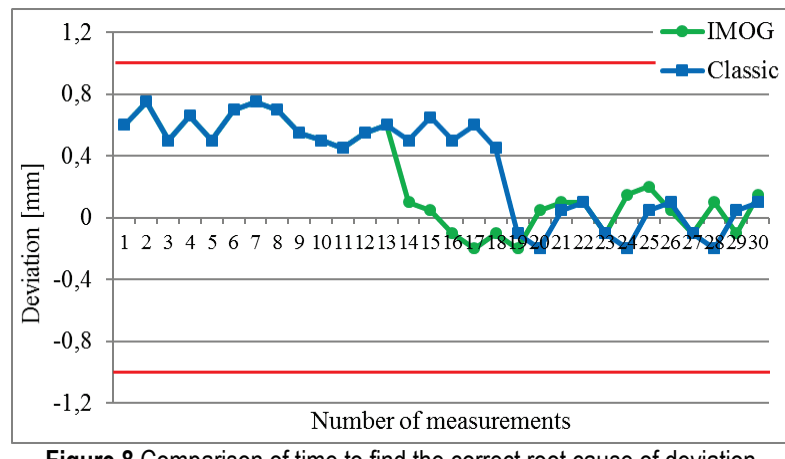

Figure 8 Comparison of time to find the correct root cause of deviation

In IMOG there is no unsubstantiated assigning of demerits to all $\mathrm{KC}$ within clusters. Detailed analysis for all anomalies allows the formation of real database and the list of real influential characteristics for the observed anomaly. That is why the evaluation of quality is good, and possible cause of the problem is clearly located in the geometry of the clusters, or in production process.

The practical verification of this concept showed that the speed of gathering and processing data is higher, procedure is simpler and possibility of errors while entering data is minimized. As data processing is automatic, there is no need for specialized personnel.

\section{CONCLUSIONS AND FUTURE WORK}

The biggest number of recent research and published papers of managing the quality is aimed at improvement of the design and pre-production phases. Modern production needs to conquer and start new production as soon as possible, so due to the lack of time and budget, computer simulations can take place before the actual production. In this way prediction of critical points and undesired events is done, attention is directed to the control of positions that simulation showed as critical. This approach has a disadvantage because it does not provide answers to questions:

- what happens if an error occurs in the position that simulation did not mark as critical, so it had not been noted because the control was focused on another place,

- $\quad$ can virtual geometry be reliable enough to replace real one,

- what to do in a situation where the development of models for a simulation takes more than one year, and during that time a new type of vehicle is developed or redesigned etc.

Offered concept is a big step forward because it focuses on the issues on the basis of the existing design (product). In other words, model IMOG is being formed based on real data. Then clearly defined answers for most questions and guidelines for further work are obtained.

Concept IMOG allows spotting the problem easily, identifying the cause and determining methods to eliminate it. Quick intervention provides return to the level defined by control plan. This at the same time gives legitimacy to demand the change of measurement and control 
procedures. In fact, IMOG allows implementation of flexible-adaptive policy of control.

Because of model properties: data driven, life cycle wide utilization of data, aiming at large scale application, new methodology can be applied to any multistage manufacturing (Fig. 9).

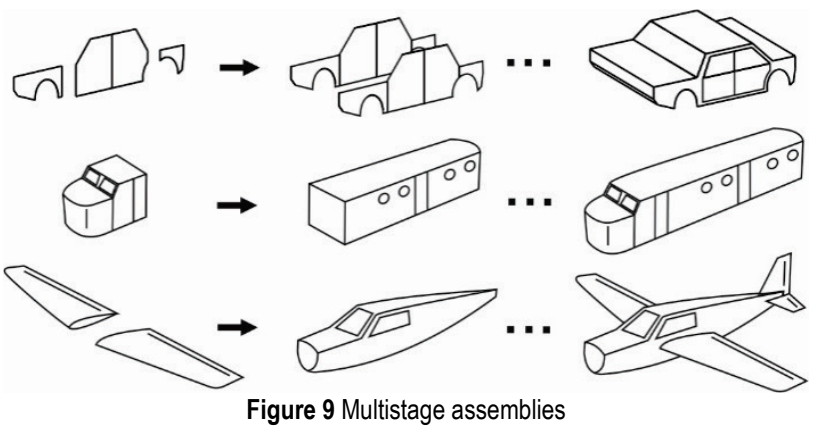

The biggest advantage is multi-layered and complete analysis, not selective, based on free will discretion, or on engineers experience. The classic approach requires decision at an early stage for one type of determination of the cause of anomalies and definition of demerits. IMOG analyzes all important parameters, provides a unique evaluation of all anomalies and based on that ranks the most critical ones. It clearly defines priority for intervention. In other words, this concept analyses the state, or to say the influence on geometry of all operations among production lines. Speed of reaching the required response is increased by more than $30 \%$ (which is practically confirmed in real condition). IMOG analysis results are almost in complete harmony with the real situation in production.

At this moment IMOG recognizes the correlation between dimensional characteristics of complete vehicle (gaps and flushes) and tools in Body and White assembly process. In this process appearance of other anomalies on body panels, such as: positive stamp, negative stamp, fitting, etc. is possible. Depending on shape and position, these anomalies are also possible to connect with the tools in the process. Next step would be adding of data inputs of all intervention on tools in process (process improvement or maintenance). The slightest intervention on the tool can be the cause of great changes on final product. If there is no constant communication between employees (who have access to the tools), sometimes it is difficult to reach the cause of the problem. Perhaps, the biggest improvement can be improvement of IMOG model application. Automated input of all data would be eliminated and that would eliminate human error, and time for solving problems would be reduced.

\section{REFERENCES}

[1] Colledani, M., Tolio T., Fischer A., Iung, B., Lanza, G., Schmitt, R., \& Vanza, J. (2014). Design and management of manufacturing systems for production quality. Manufacturing Technology, 63, 773-796. https://doi.org/10.1016/j.cirp.2014.05.002

[2] Chen, W. \& Hao, Y. F. (2018). Genetic Algorithm-Based Design and Simulation of Manufacturing Flow Shop Scheduling. International Journal of Simulation Modelling, 17(4), 702-711. https://doi.org/10.2507/IJSIMM17(4)C017
[3] Supsomboon, S. \& Vajasuvimon, A. (2016). Simulation Model for Job Shop Production Process Improvement in Machine Parts Manufacturing. International Journal of Simulation Modelling, 15(4), 611-622. https://doi.org/10.2507/IJSIMM15(4)3.352

[4] Radej, B., Drnovsek, J., \& Beges, G. (2017). An overview and evaluation of quality-improvement methods from the manufacturing and supply-chain perspective. Advances in Production Engineering \& Management, 12(4), 388-400. https://doi.org/10.14743/apem2017.4.266

[5] Parker, J. (2017). The Root of the Matter. Internal auditor, 74(4), 53-59. Database: MasterFILEPremie.

[6] Hu, S. J. (1997). Stream of Variation Theory for Automotive Body Assembly. Annals of CIRP, 46(1), 1-8. https://doi.org/10.1016/S0007-8506(07)60763-X

[7] Jin, J. \& Shi, J. (1999). State-space modeling of sheet metal assembly for dimensional control. Trans. ASME, J. Mfg Sci. Technol. 121(4), 756-762. https://doi.org/10.1115/1.2833137

[8] Ding, Y., Ceglarek, D., \& Shi, J. (2000). Modeling and diagnosis of multistage manufacturing processes. Part I: state space model. In Proceedings of the Japan-USA Symposium on Flexible Automation, Ann Arbor, Michigan.

[9] Huang, Q., Zhou, N., \& Shi, J. (2000). Stream of variation modeling and diagnosis of multi-station machining processes. In Proceedings of the International Mechanical Engineering Congress and Exposition (IMECE).

[10] Djurdjanovic, D. \& Ni, J. (2001). Linear state space modeling of dimensional machining errors. Trans. NAMRI \pm SME, 29, 541-548.

[11] Zhou, S., Huang, Q., \& Shi, J. (2001). State-space modeling of multistage machining systems by using differential motion vector. IEEE Trans. Robotics Autumn.

[12] Hu, S. \& Wu, S. M. (1992). Identifying Root Causes of Variation in Auto-Body Assembly Using Principal Component Analysis. Transactions of NAMRI, 20, 311-316.

[13] Ceglarek, D., Shi, J., \& Wu, S. M. (1994). A KnowledgeBased Diagnostic Approach for the Launch of the AutoBody Assembly Processes. ASME Journal of Engineering for Industry, 116, 491- 499. https://doi.org/10.1115/1.2902133

[14] Appley, D. \& Shi, J. (1998). Diagnosis of Multiple Fixture Faults in Panel Assembly. ASME Journal of Manufacturing Science and Engineering, 120, 793-801. https://doi.org/10.1115/1.2830222

[15] Huang, Q., Zhou, N., \& Shi, J. (2000). Stream of Variation Modeling and Diagnosis of Multi-Station Machining Processes. Proc. of the Int. Mech. Eng. Congress and Exposition. Orlando, FL.

[16] Kondić, Ž. \& Maglić, L. (2008). Poboljšanja u sustavu upravljanja kvalitetom metodologijom "Lean Six Sigma". Tehnički vjesnik, 15(2), 41-47.

[17] Giocoechea, I. \& Fenollera, M. (2012). Quality Management in the Automotive Industry. Chapter 51 in DAAAM International Scientific Book 2012, 619-632. https://doi.org/10.2507/daaam.scibook

[18] Technical Specification (2009). Quality management systems - Particular requirements for the application of ISO 9001:2000 for automotive production and relevant service part organizations, ISO/TS 16949:2009, 2, 3.1.1

[19] Quality Assurance Policy and Procedures (2014). Publications and Information Products, Version: e6v3. Commission for Environmental Cooperation, Montréal

[20] International Standard (2015). Quality management systems - Fundamentals and vocabulary. ISO 9000:2015

[21] Quality Assurance and Quality Control Process (2005). Guide for Project Managers. MDOT Trunk line Projects.

[22] Soderblom, R. (2015). The Basic of Geometry Assurance. Project Report. University West, Department of Engineering Science, Sweden. 
[23] Ketan, H. \& Nassir, M. (2016). Aluminium hot extrusion process capability improvement using Six Sigma. Advances in Production Engineering \& Management, 11(1), 59-69. https://doi.org/10.14743/apem2016.1.210.

[24] Volchuk, V., Klymenko, I., Kroviakov, S., \& Oreskovic, M. (2018). Method of material quality estimation with usage of multifractal formalism. Tehnicki glasnik, 12(2), 93-97. https://doi.org/10.31803/tg-20180302115027

[25] Engin, K. E. \& Eyercioglu, O. (2017). The Effect of the Thickness-to-Die Diameter Ratio on the Sheet Metal Blanking Process. Strojniski vestnik-Journal of Mechanical Engineering, 63(9), 501-509. https://doi.org/10.5545/sv-jme.2016.4272

[26] Lee, D. J. \& Thornton, A. C. (1996). The Identification and Use of Key Characteristics in the Product Development Process. The 1996 ASME Design Engineering Technical Conferences and Campus in Engineering Conference, August 18-22, Irvine, California, USA, American Society of Mechanical Engineers.

[27] Belić, Ž. \& Majstorović, V. (2015). Determining the cause for variable geometry of the part of body in white and providing solutions. International Working Conference 'Total Quality Management - Advanced and Intelligent Approaches', Belgrade, Serbia.

[28] Doboviček, S., Mikac, T., \& Damiani, D. (2013). Logical Procedure for determining the appropriate method of calculating the process capability. Tehnički vjesnik, 20(5), 739-746.

\section{Contact information:}

\section{Živorad BELIĆ, MSc}

Cooper Standard Srbija d.0.0.

Dimitrija Davidovića 1, 22000 Sremska Mitrovica, Serbia

beliczivorad@gmail.com

\section{Vidosav MAJSTOROVIĆ, Prof. Dr}

University of Belgrade, Mechanical Engineering Faculty,

Kraljice Marije 16, 11000 Belgrade, Serbia

vmajstorovic@mas.bg.ac.rs

\section{Dragan ĐURĐANOVIĆ, Prof. Dr}

Mechanical Engineering University of Texas at Austin,

Ann Arbor, MI 48109-2125, USA

dragand@me.utexas.edu

\section{Snežana KIRIN, Dr, Senior scientist}

Inovation Center of Mechanical Engineering,

Kraljice Marije 16, 11000 Belgrade, Serbia

snezanakirin@yahoo.com 